\title{
Air force clips the wings of UK wind power
}

Laura Nelson, London

Britain's bold plans to generate more electricity from wind energy may be shot down by the Royal Air Force (RAF), which says that wind farms confuse its air-defence radar system.

But wind-energy advocates are pressing the air force to ease up on rules that currently prohibit wind turbines from being located within a radius of 74 kilometres of any of its 13 air-defence radar stations.

Earlier this month, the Royal Society, Britain's science academy, intervened in the dispute. It wrote to both the Department of Trade and Industry (DTI) and the Ministry of Defence $(\mathrm{MoD})$ to point out that the RAF's stipulation could derail government plans to generate $10 \%$ of electrical power from renewable sources by 2010 .

David Wallace, the society's vicepresident, wrote in the letter that nearly half of the wind farms proposed so far in Britain have been successfully opposed by the MoD because of their proximity to air-defence stations. Wallace said that the restrictions were a "significant obstacle on the prospects for developing the UK wind industry".

On 1 March, the society gave written evidence to an inquiry by the House of Lords Science and Technology Committee on renewable energy. The society said that it was concerned about the number of applications for wind farms that had been turned down.

The MoD says that the 30- to 40-metrelong blades used on typical wind turbines can mask radar signals from low-flying aircraft or produce false alarms by reflecting radar

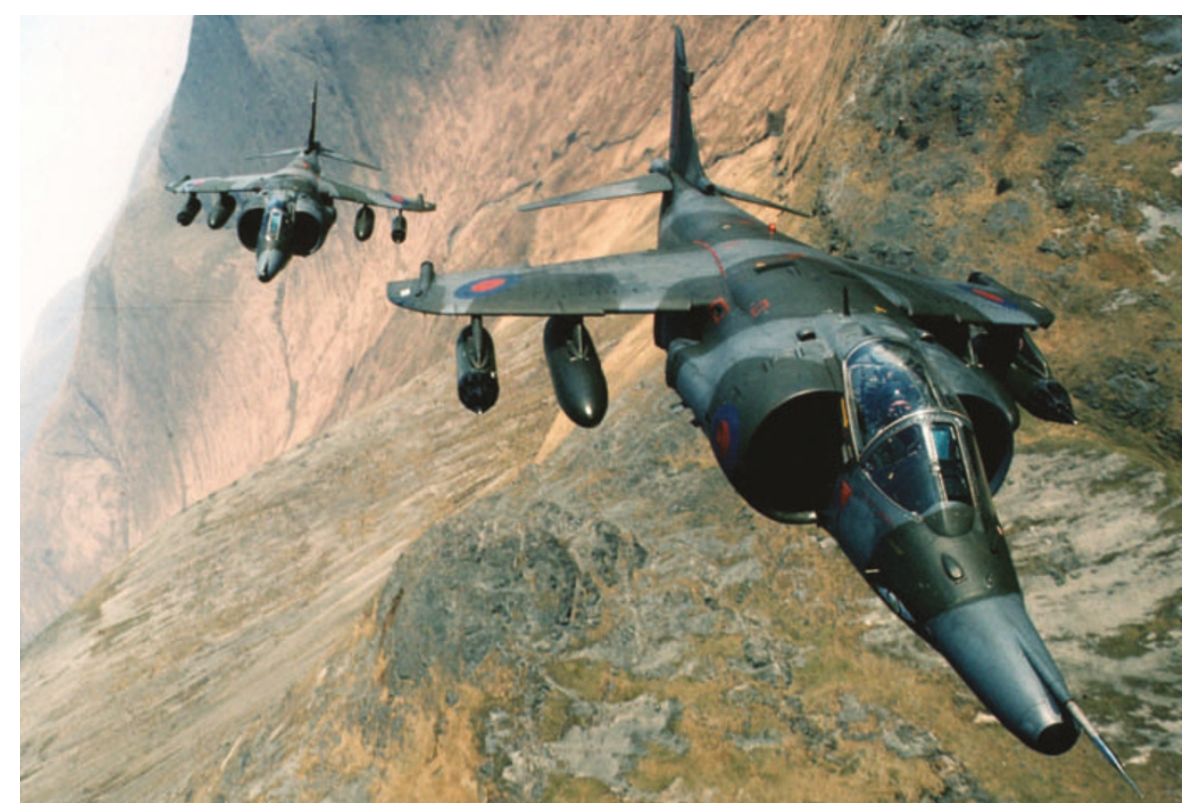

Outmanoeuvred: radar stations struggle to tell the difference between low-flying jets and wind turbines.

beams. The wind-farm restriction is based on two RAF studies carried out in 1994 and 1997, the contents of which remain classified.

Other European countries do not impose such restrictions. Germany, for example, demands a distance of only $5 \mathrm{~km}$ between wind farms and radar stations. But MoD officials say that there are more low-flying aircraft in the United Kingdom.

A working group of representatives from the MoD, the DTI, the Civil Aviation Authority and the British Wind Energy Association was set up two years ago to address the problem. But it has so far failed to agree on whether the MoD rule is technically justified.

Instead, the group has discussed ways to avoid the problem, such as using radar systems that can distinguish between wind turbines and aircraft. The MoD may implement the more sophisticated radar in 2008 , but the system is expensive and the ministry does not believe it will completely solve the problem. The Royal Society is urging government ministers to step in and resolve the dispute.

\section{Scheme to track rare dolphins hits troubled waters}

David Cyranoski, Auckland

A plan to help save one of the smallest and rarest species of dolphin has divided conservation biologists.

New Zealand's conservation department wants to track between 10 and 50 Maui's dolphins (Cephalorhynchus hectori maui) by attaching a satellite tracking device to their fins. But critics are concerned that the plan could do more harm than good.

Only about 150 of the 1.7-metre long dolphins remain, and government officials say that the tags could be used to direct fishing boats away from the mammals.

In the past three years, seven Maui's have been washed up on New Zealand's shores, probably as a result of becoming tangled in fishing nets, says Rob McCallum, a senior scientist at the conservation department. "In a population of 150 dolphins, that's a lot," he says.

But the 50-gram transmitter tags, which are fixed to a fin by two nylon pins, could upset and injure the dolphins - or even kill them, say critics. Maui's are much smaller than most of the other mammals on which the technology has been tested, they note.

In a letter to McCallum last November, Nick Gales, a biologist at the World Conservation Union, called for a "thorough risk assessment" before the technique was

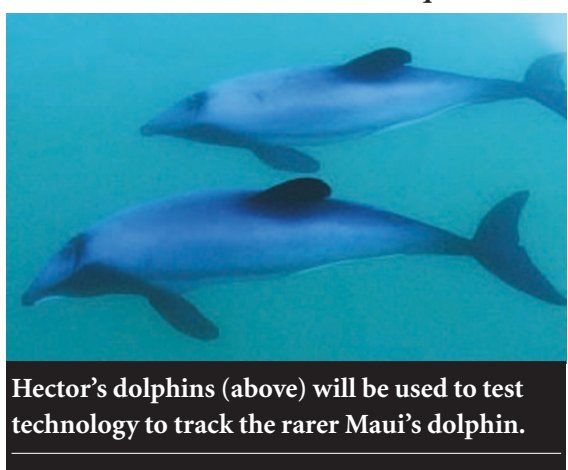

used on the Maui's. "The level of concern is particularly high for the smaller species, given that the potential impact of the tag is related in part to the size of the animal," he wrote.

And in a report this January, Ian West and Simon Childerhouse, marine-mammal specialists at the conservation department, questioned how useful the tagging data would prove to be. They recommended that non-invasive methods, such as aerial sightings, be used instead.

But on 5 March, the conservation department began a three-month trial to test both the safety and usefulness of the tagging system. Researchers have tagged three Hector's dolphins, which are close relatives of the Maui's and are roughly the same size.

McCallum, who is managing the trial, says that satellite tracking has to be tested, even if it carries some risks. "We are not prepared to just watch as this species slides into extinction," he says. 